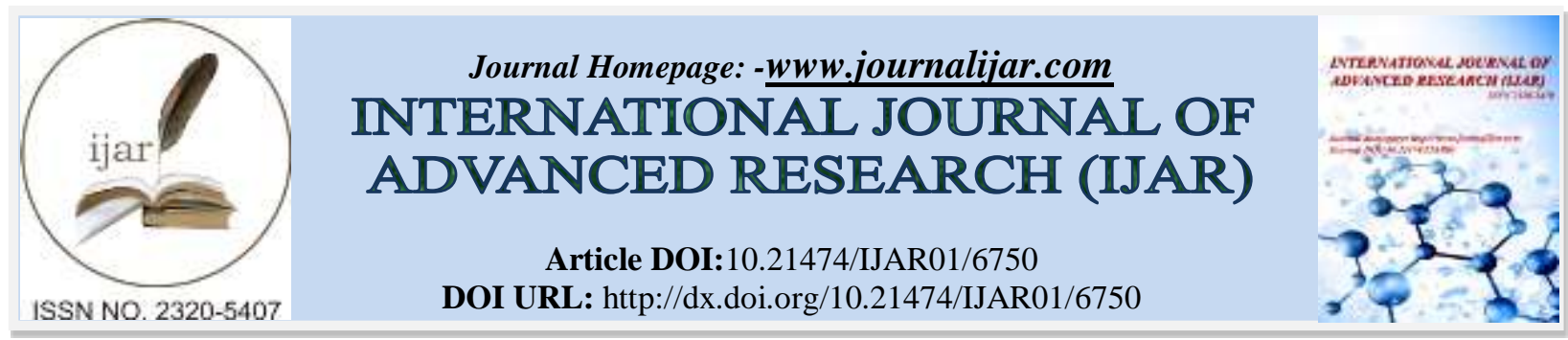

RESEARCH ARTICLE

\title{
GENOTYPE BY ENVIRONMENT INTERACTION AND STABILITY ANALYSIS OF SEED YIELD, AGRONOMIC CHARACTERS IN MUNGBEAN (Vigna radiata L. Wilczek) GENOTYPES.
}

\author{
Kyaw Swar Win ${ }^{1}$, Kyi Win ${ }^{2}$, Than Da Min², Nyo Mar Htwe ${ }^{2}$ and Tun Shwe ${ }^{1}$. \\ 1. Food Legumes Section, Department of Agricultural Research, Yezin, Myanmar. \\ 2. Department of Plant Breeding, Physiology and Ecology, Yezin Agricultural University, Myanmar.
}

\section{Manuscript Info}

Manuscript History

Received: 15 January 2018

Final Accepted: 17 February 2018

Published: March 2018

Keywords:-

Additive main effects and multiplicative interactions (AMMI), stability analysis, biplot, mungbean.

\section{Abstract}

Field experiments were conducted in monsoon season, 2011 at Food Legumes Section, Department of Agricultural Research (DAR), Yezin, Tatkon Research Farm and Sebin Research Farm by using Randomized Complete Block Design with four replications. Seven mungbean breeding lines (three lines from Yezin-9 x VC-6371-23-11, three lines from NM-92 x VC-6368-46-40 and one line from NM-92 mutant) and six released varieties were used to examine the genotype $\mathrm{x}$ environment $(\mathrm{G} \times \mathrm{E})$ interaction on seed yield and to identify stable and high yielding mungbean genotypes across environments. Genotype $\mathrm{x}$ environment interaction was observed in all recorded characters except for seeds per pod. $\quad M$ e a $n$ s e d y i e $1 \mathrm{~d}$ perform a n e in three e $n$ viro n m e n t s i n d i c a t e d g e n o t y p e YM-03-2-6 which produced the highest seed yield of $9.73 \mathrm{~g}$ per plant followed by Yezin-9 $(9.57 \mathrm{~g})$. YM-03-2-6 and Yezin-9 were stable genotypes with high mean yield that genotypes produced close to unity $\left(b_{i}=1\right)$, non significant differences from regression coefficient $\left(b_{i}\right)$ and deviation from regression $\left(S_{d i}^{2}\right)$ due to stability analysis with close to the zero of IPCA scores from the results of AMMI analysis. Genotype YM-03-2-5 produced average mean yield with high $b_{i}$ and $S_{d i}^{2}$ value and coupled with high positive interaction in Tatkon Research Farm while genotype YM-03-2-2 also produced average yield mean yield with low $b_{i}$ and high $S_{d i}^{2}$ value and coupled with high positive interaction in Sebin Research Farm. This showed that genotype YM-03-2-5 and YM-03-22 were better responsive to high yielding environment and poor environment, respectively. So, both the Stability analysis (Eberhart and Russell, 1966) and additive main effects and multiplicative interactions (AMMI) analysis considered YM-03-2-6 and Yezin-9 could be used as broad adaption varieties with high yield in all tested environments. Genotypes that could be used as good adaptation to specific environments were YM-03-2-5 for Tatkon Research Farm and YM-032-2 for Sebin Research Farm. 


\section{Introduction:-}

Mungbean [Vigna radiata (L.)Wilczek] is a short duration legume crop cultivated primarily for their dry seeds. While the areas for cereals and other pulses have decreased, that for mungbean has doubled in the last two decades with an annual rate of $2.5 \%$. This growth may very likely continue since mungbean's short-growth duration (60 days) makes it suitable for the various cropping systems. Annual mungbean production worldwide is around 2.5 to 3.0 million metric tons harvested from about 5.0 million ha (Poehlman 1991). Around $45 \%$ of the total world mungbean production is in India. In China, mungbean is growing about 0.5 million ha per year with an average of 2 t/ha yield (Poehlman 1991). In Thailand and the Philippines, mungbean is the most important grain legume; in Sri Lanka it ranks second, while in India, Myanmar, Bangladesh and Indonesia it is the third most important grain legume.

Mungbean is one of the major pulses in Myanmar. It occupied the largest area about one million hectare. Annual production of mungbean was about 1410,000 metric tons in 2010 - 2011(MOAI 2011). National target yield of mungbean in Myanmar is $1600 \mathrm{~kg}$ per hectare, but the yield of mungbean in 2010 - 2011was $1260 \mathrm{~kg}$ per hectare (MOAI 2011). The theoretical limit of mungbean productivity was suggested to be 3.8 tons/ha based on the amount of light energy available in the field (Agugo and Chukwu 2009). Even this level has not been achieved in tropical countries, where low productivity is mainly due to the short growing periods available in subtropical conditions, limited varietal stability, and narrow genetic base of cultivars (Singh and Hymowitz 2001). Therefore, it is needed to attempt to reach national target yield. The production constraints in mungbean are low yield potential, lack of yield stability, susceptibility to major diseases and pests, narrow adaptability due to photoperiod and temperature sensitivity and susceptibility to abiotic stresses such as drought, flood, non synchronous maturity and pod shattering (Fernandez and Shanmugasundaram 1988).

Use of stable cultivars over several environments for high seed yield and quality characteristics is important for many crops. When cultivars are tested in terms of seed yield at the multi-environmental trials, great differences are commonly observed in yield performance over environments. This different yield response of cultivars from one environment to another is called genotype x environment ( $\mathrm{G} \mathrm{x} \mathrm{E}$ ) interaction (Allard 1960; Vargas et al. 1998). Raffi et al. (2004) reported that genotype $x$ environment interaction is of much value in the selection of better genotypes. $\mathrm{G} \times \mathrm{E}$ interaction should be investigated so that the breeder can decide to restructure the programme to minimize the interaction effect, or exploit it to produce varieties with specific adaptation to particular environments (Eisemann et al. 1990). The interaction indicates that genotypes react in different ways to variable environmental condition. A key concept in G x E analysis is genotype stability and by definition, genotypes exhibiting a high degree of $\mathrm{G} \times \mathrm{E}$ interaction are unstable across sites (Berger et al. 2007). The assessment of stability and wider adaptability of breeding lines against biotic and abiotic stresses is a pre-requisite in any breeding programme. Stability in performance of a genotype over a wide range of environment is a desirable attribute and depends on magnitude of genotype $\mathrm{x}$ environment interaction (Ahmad et al. 1996). The stability of seed yield in different crops has statistically evaluated through analysis of $\mathrm{G}$ x E interaction in cultivar adaptation traits conducted over several environments (Crossa 1990; Piepho 1998). Environmental factors such as soil moisture, sowing time, fertility, temperature and day length have strong influence during various stages of plant growth (Bull et al. 1992).

The environment is changing day by day and it is directly needed to evaluate crop genotypes at different locations to evaluate their performances. Thus, this research was conducted to examine the genotype $\mathrm{x}$ environment interaction on seed yield and agronomic characters of mungbean genotypes, and to identify stable and high yielding mungbean genotypes under changing environments.

\section{Materials And Methods:-}

Field experiments were conducted at Food Legumes Section, Department of Agricultural Research (DAR), Yezin $\left(19^{\circ} 51^{\prime} \mathrm{N}\right.$ latitude and $96^{\circ} 7^{\prime} \mathrm{E}$ longitude at $97 \mathrm{~m}$ altitude), Tatkon Research Farm $\left(20^{\circ} 08^{\prime} \mathrm{N}\right.$ latitude and $96^{\circ} 12^{\prime} \mathrm{E}$ longitude at $145 \mathrm{~m}$ altitude) and Sebin Research Farm ( $\left(20^{\circ} 31^{\prime} \mathrm{N}\right.$ latitude and $96^{\circ} 3^{\prime} \mathrm{E}$ longitude at $213 \mathrm{~m}$ altitude) in monsoon season (May - August)2011.The meteorological data and physical and chemical properties of soil at growing season of tested sites were shown in Appendix.1 and Appendix.2, respectively.

Thirteen mungbean genotypes were used in these experiments (Table 1). these genotypes, seven genotypes were breeding lines and six genotypes were released genotypes. Among the seven breeding lines, three lines (YM 03-2-2, 
YM 03-2-5 and YM 03-2-6) were derived from Yezin-9 x VC-6371-23-11, three lines (YM-03-4-11, YM-03-4-20 and YM-03-4-21) were developed from NM-92 x VC-6368-46-40 and one lines (YM-04-M-26) from NM-92 mutant. These seven breeding lines were obtained from national breeding program of Food Legumes Section, DAR. Among six released varieties, five varieties were developed from DAR and one variety was developed from Department of Agriculture (DOA). Randomized complete block design with four replications was used in this study. The plot size was $5 \mathrm{~m} \mathrm{x} 2 \mathrm{~m}$ with 4 rows. The row length was $5 \mathrm{~m}$ long and $45 \mathrm{~cm}$ and $10 \mathrm{~cm}$ distances between rows and plants, respectively. The fertilizers were applied in soil preparation at the rate of $62 \mathrm{~kg}$ per hectare of triple super phosphate, $62 \mathrm{~kg}$ per hectare of muriate of potash and one packet $(150 \mathrm{~g})$ of rhizobium. Normal cultural practices and plant protection measures were followed in each trial. Grain yield data was recorded on five randomly selected plants from each genotype in each replication. Analysis of variance for each environment, combined analysis of variance across the tested environments and stability parameters: $\mathrm{r}$ e g r e s s i o $\mathrm{n}$

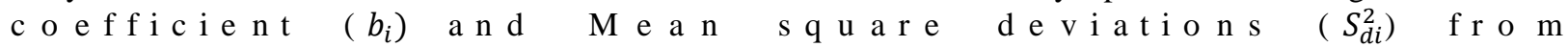
li n e a r r e g r e s s i o $n$ were performed by using CROPSTAT, version 7.2 whereas

The G x E interaction was analysed in AMMI (Additive Main and Multiplicative Interaction) model with a view to identify mungbean genotypes better adapted to different locations by using GenSTAT Discovery Edition 4.

Table 1:- List of tested mungbean genotypes and their sources

\begin{tabular}{|l|l|l|c|}
\hline No. & \multicolumn{1}{|c|}{ Genotype } & \multicolumn{1}{|c|}{ Line no. } & Sources \\
\hline 1. & YM 03-2-2 & Yezin-9 x VC-6371-23-11 & Myanmar \\
\hline 2. & YM 03-2-5 & Yezin-9 x VC-6371-23-11 & Myanmar \\
\hline 3. & YM 03-2-6 & Yezin-9 x VC-6371-23-11 & Myanmar \\
\hline 4. & YM 03-4-11 & NM-92 x VC-6368-46-40 & Myanmar \\
\hline 5 & YM 03-4-20 & NM-92 x VC-6368-46-40 & Myanmar \\
\hline 6. & YM 03-4-21 & NM-92 x VC-6368-46-40 & Myanmar \\
\hline 7. & YM 04-M-26 & NM-92 mutant & AVRDC \\
\hline 8. & Yezin -5 & V-3726 & AVRDC \\
\hline 9. & Yezin -7 & VC-5205-A & AVRDC \\
\hline 10. & Yezin -9 & VC-1973-A & AVRDC \\
\hline 11. & Yezin -10 & NM-92 & AVRDC \\
\hline 12. & Yezin -11 & NM-94 & AVRDC \\
\hline 13. & MAS -1 & VC-6469-1-2-4A & \\
\hline
\end{tabular}

Appendix 1 Physical and chemical properties of soil und er different environments

\begin{tabular}{|c|c|c|c|c|c|c|c|c|c|c|}
\hline \multirow{2}{*}{ No. } & \multirow{2}{*}{ Environment } & \multirow{2}{*}{$\mathrm{pH}$} & \multicolumn{3}{|c|}{ Available } & \multirow{2}{*}{$\begin{array}{c}\text { Organic } \\
\text { matter }(\%)\end{array}$} & \multicolumn{3}{|c|}{ Soil Texture (\%) } & \multirow{2}{*}{ Soil class } \\
\hline & & & $\mathrm{N}(\mathrm{ppm})$ & $P(\mathrm{ppm})$ & $\mathrm{K}(\mathrm{ppm})$ & & Sand & Silt & Clay & \\
\hline 1. & Yezin & 6.51 & 48 & 5 & 103 & 1.84 & 85.28 & 7.51 & 7.21 & Loamy sand \\
\hline 2. & Tatkon & 7.43 & 70 & 5 & 113 & 1.31 & 87.47 & 6.96 & 5.57 & Loamy sand \\
\hline 3. & Sebin & 8.13 & 62 & 4 & 60 & 1.47 & 79.02 & 9.78 & 11.20 & Sandy loam \\
\hline
\end{tabular}

Source: Soil Science Section, Soil Science, Water Utilization and Agricult ural Engineering Division, DAR

Appendix 2:- Rainfall, mean minimum and maximum temperature ( $\mathrm{C}$ ) during growing seasons 

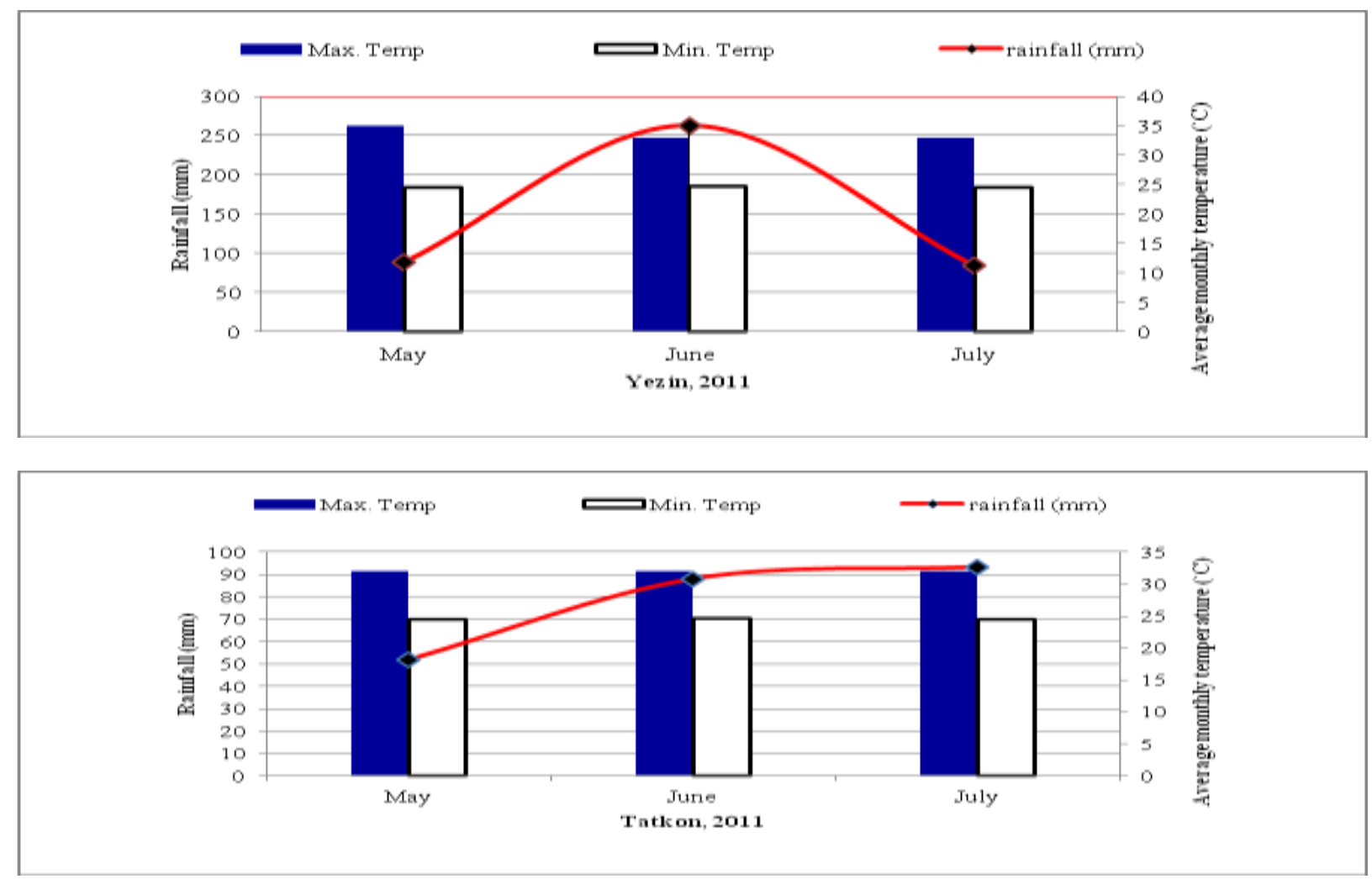

\section{Results And Discussion:-}

The results of stability parameters such as regression coefficient $\left(b_{i}\right)$ and mean square deviation from regression $\left(S_{d i}^{2}\right)$ for seed yield per plant of tested mungbean genotypes are presented in Table 4.12. The mean values of seed yield per plant over three seed yield with $9.73 \mathrm{~g}$ per plant whereas Yezin-10 produced the poor performance with $6.93 \mathrm{~g}$ per plant over environments. On the bases of mean yield ranking; YM-03-2-6 and Yezin-9 were the top yielding genotypes across environments.

The value of regression coefficient $\left(b_{i}\right)$ and mean square deviation from regression $\left(S_{d i}^{2}\right)$ was used in this study ranged from 0.23 to 1.65 and -0.40 to 3.30 , respectively (Table 2). Finlay \& Wilkinson (1963) reported that the regression coefficient ' $b_{i}$ ' is a measure of stability in crop plants. Eberhart \& Russell (1966) proposed that both regression coefficient ' $b_{i}$ ' and mean square deviation from regression coefficient ' $S_{d i}^{2}$ ' may be taken into consideration in identifying stable genotypes. So, a genotype with ' $b_{i}$ ' value $<1.0$ has above average stability and is specially adapted to low performing environments, a cultivar with ' $b_{i}$ ', value $>1.0$ has below average stability and is specially adapted to high performing environments and a cultivar with ' $b_{i}$ ' value equal to 1.0 has average stability and is well or poorly adapted to all environments depending on having a high or low mean performance (Finlay \& Wilkinson, 1963) but a genotype with $b_{i}=1.0$ and $S_{d i}^{2}=0.0$ may be defined as stable (Eberhart \& Russell, 1966).

The results of phenotypic stability (Eberhart and Russell method) indicated that the value of regression coefficient did not significantly differ from unity $\left(b_{i}=1\right)$ and the values of mean square deviation from regression $\left(S_{d i}^{2}\right)$ were not significantly different from zero $\left(S_{d i}^{2}=0\right)$ for the studied genotypes (Table 4.12). With this view, YM-03-2-6, Yezin-9 and Yezin-10 produced close to unity $\left(b_{i}=1\right)$ and non significant differences from regression coefficient $\left(b_{i}\right)$ and mean square deviation from regression $\left(S_{d i}^{2}\right)$. So, YM-03-2-6 and Yezin-9 were stable varieties with high mean yield whereas Yezin-10 was a stable variety with low mean yield. Yezin-11, YM-04-M-26, YM-03-4-20, Yezin-5 and Yezin-7 possessed average yield stability with low $S_{d i}^{2}$ value and this indicated that genotypes were best suited to high yielding environments. Genotype YM-03-4-11, MAS-1 and YM-03-4-21 produced low, non significant $b_{i}$ and $S_{d i}^{2}$ value and its indicated better response to poor environments. Genotype YM-03-2-5 had average yield with high $b_{i}$ and $S_{d i}^{2}$ value and this showed that this genotype was better responsive to favourable environment, whereas genotypes YM-03-2-2 produced average mean yield with low $b_{i}$ and high $S_{d i}^{2}$ value and this 
indicated that genotype YM-03-2-2 was suited to poor environment (Figure 4.1). Lai et al. (1974), Nassib et al. (1986), Abo El-Zahab et al. (1986), Omar et al. (1999), Redden et al. (2000), Truberg and Huehn (2000) and Sabah etal. (2007) who reported that adaptability and phenotypic stability estimates showed that there was generally wide adaptability and stable performance of genotypes in the environments.

Table 2:- Mean performances of seed yield per plant $(\mathrm{g})$ and stability parameters for tested mungbean genotypes estimated by Eberhart and Russell (1966) model in Yezin (DAR), Tatkon and Sebin Research Farm (2011)

\begin{tabular}{|l|l|l|l|l|l|l|l|}
\hline No. & Genotype & Yezin & Tatkon & Sebin & Mean & $\mathbf{b}_{\mathbf{i}}$ & \multicolumn{1}{|c|}{$\boldsymbol{S}_{\boldsymbol{d i}}^{\mathbf{2}}$} \\
\hline 1 & YM 03-2-2 & 7.47 & 8.78 & 10.35 & 8.86 & 0.42 & 2.48 \\
\hline 2 & YM 03-2-5 & 6.73 & 11.28 & 6.99 & 8.34 & $\mathbf{1 . 1 8}$ & 3.30 \\
\hline 3 & YM 03-2-6 & 7.71 & 12.13 & 9.37 & 9.73 & $\mathbf{1 . 1 9}$ & $\mathbf{0 . 0 8}$ \\
\hline 4 & YM 03-4-11 & 7.43 & 8.35 & 7.04 & 7.61 & 0.23 & $\mathbf{0 . 0 9}$ \\
\hline 5 & YM 03-4-20 & 5.75 & 10.30 & 7.70 & 7.91 & 1.23 & -0.15 \\
\hline 6 & YM 03-4-21 & 5.87 & 7.88 & 7.49 & 7.08 & 0.57 & -0.34 \\
\hline 7 & YM 04-M-26 & 5.09 & 10.41 & 7.09 & 7.53 & 1.43 & 0.32 \\
\hline 8 & Yezin - 5 & 5.47 & 10.14 & 9.13 & 8.25 & 1.31 & 0.10 \\
\hline 9 & Yezin - 7 & 4.06 & 9.92 & 8.76 & 7.58 & 1.65 & 0.61 \\
\hline 10 & Yezin - 9 & 7.59 & 10.44 & 10.70 & 9.57 & $\mathbf{0 . 8 3}$ & 0.91 \\
\hline 11 & Yezin - 10 & 4.86 & 8.62 & 7.32 & 6.93 & $\mathbf{1 . 0 4}$ & -0.43 \\
\hline 12 & Yezin - 11 & 5.79 & 10.54 & 8.90 & 8.41 & 1.32 & -0.40 \\
\hline 13 & MAS - 1 & 7.23 & 9.46 & 7.72 & 8.14 & 0.59 & $\mathbf{- 0 . 0 4}$ \\
\hline & Mean & 6.23 & 9.86 & 8.35 & $\mathbf{8 . 1 5}$ & & \\
\hline
\end{tabular}

$b_{i}=$ Regression coefficient

$S_{d i}^{2}=$ Deviation from regression

YM-03-2-5

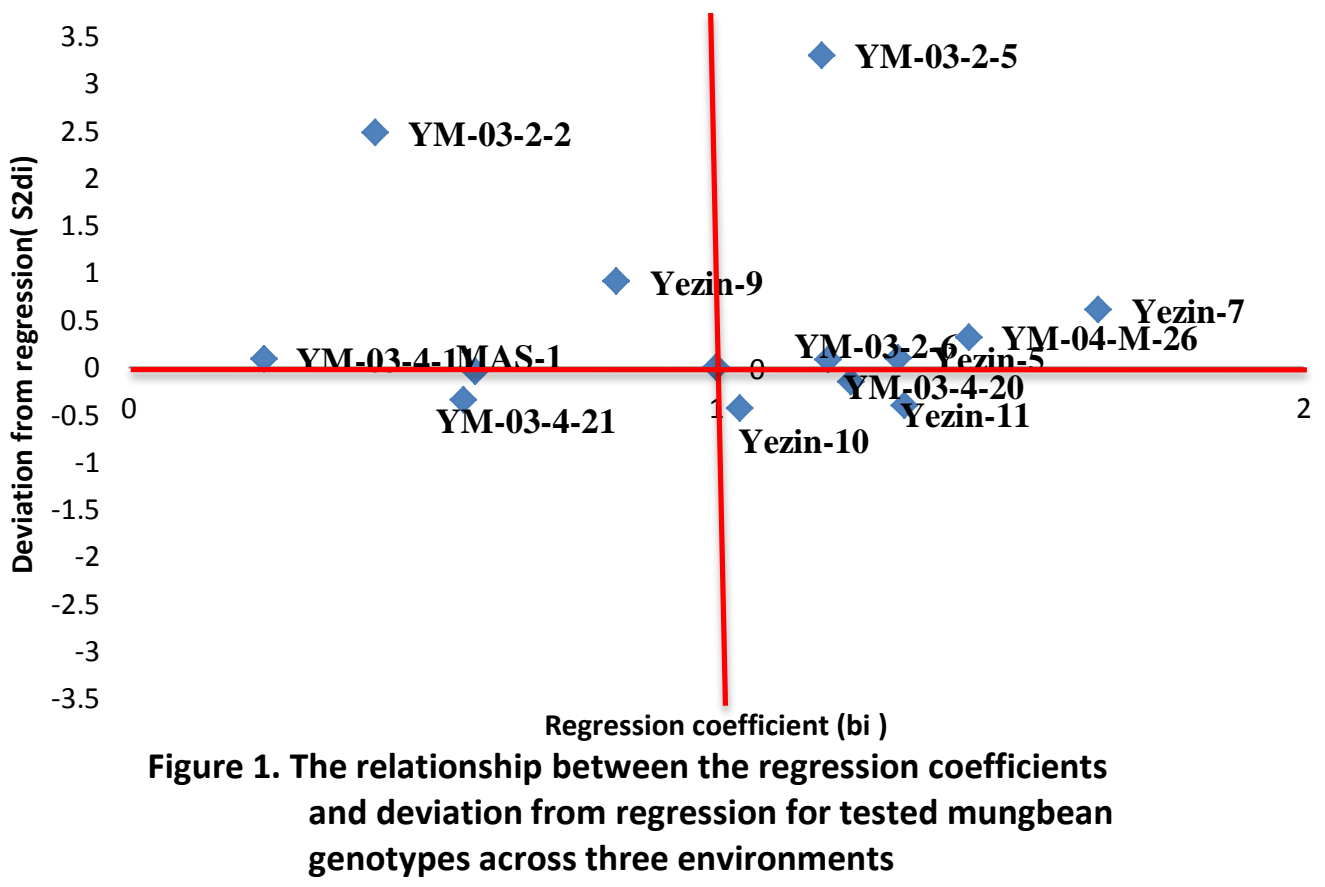


AMMI analysis of variance for seed yield per plant of tested mungbean genotypes across environments showed that genotypes $(\mathrm{G})$ and environment (E) and the $\mathrm{G} \times \mathrm{E}$ interaction were highly significant (Table 3 ). The main effects of genotype and environment accounted for $18.88 \%$ and $61.40 \%$, respectively and $\mathrm{G} \times \mathrm{E}$ interaction accounted for $19.7 \%$ of the total variation for seed yield per plant. This indicated that the environments were diverse and caused the greatest variation in seed yield per plant. The $\mathrm{G}$ x E sum of squares was larger than that of genotypes, which determined differences in genotypic response across environments. Tarakanovas and Ruzgus (2006), Misra et al. (2009) and Das et al. (2010) reported significant G×E interaction for grain yield and stressed the usefulness of AMMI analysis for selection of promising genotypes for specific locations or environmental conditions.

Genotype $\mathrm{x}$ environment interaction effects of genotypes in different locations (Table 4.) showed that genotype YM03-4-11 had high positive interaction (1.74) and Yezin-7 had high negative interaction (-1.61) with the environment of Yezin (DAR). Genotype YM-03-2-5(1.23) and YM-04-M-26 (1.17) showed high positive interaction and YM-032-2 had high negative interaction (-1.80) at Tatkon Research Farm whereas genotype YM-03-2-2 had high positive interaction (1.29) and YM-03-2-5 showed high negative interaction (-1.54) at Sebin Research Farm. This indicated that these genotypes showed differential performance across environ -ments.

The analysis of AMMI showed that two interactions of principal component analysis (IPCA 1, IPCA 2) were highly significant, of which IPCA 1 component was accounted for $56.14 \%$ of total $\mathrm{G} \mathrm{x} \mathrm{E} \mathrm{interaction} \mathrm{sum} \mathrm{of} \mathrm{squares.} \mathrm{Biplot}$ analysis is the most powerful interpretive tool in analysis of G x E interaction in AMMI model and permits easy visualization of differences in interaction effects. In AMMI I biplot, the IPCA 1 scores of genotypes and environments are plolted against their respective means and in AMMI II biplot, the IPCA 1 and IPCA 2 scores of genotypes and environments are plotted against each other.

AMMI I biplot for seed yield per plant of tested mugbean genotypes at three environmental conditions is presented in Fig.2. The main effects (Genotypes and Environments) accounted for $80.28 \%$ and IPCA 1 accounted for $11.06 \%$ of total variation in genotype $\mathrm{x}$ environment interaction and so the AMMI I biplot gave a model fit of 91.34\%. The scatter of the genotype points in the AMMI I biplot was divided into four quadrants from lower yielding environments in quadrants I and IV to high yielding in quadrants II and III (Fig. 1).

The biplot explains not only the average yield of a genotype but also how it is achieved. According to biplot, YM03-2-6, Yezin-5, Yezin-9 and Yezin-11 showed higher grand mean yield and stability across the environments by being close to the zero of IPCA scores. Genotypes YM-03-2-6 and Yezin-9 showed higher yield above the grand mean yield but it is less stable than Yezin-10 which was closed to the zero of IPCA score with low yield.

AMMI II biplot for seed yield per plant of tested mungbean genotypes across en- vironment is presented in Fig. 2. The IPCA I component accounted for $56.14 \%$ of $\quad \mathrm{G} x \mathrm{E}$ interaction, while IPCA 2 accounted for $43.86 \%$. Distribution of genotypes points in the AMMI II biplot revealed that YM-03-2-6, YM-03-4-20, YM-03-4-21, YM04-M-26, Yezin-5, Yezin-9, Yezin-10, Yezin-11and MAS-1 scattered close to the origin and this indicated that these genotypes showed minimal interaction with environments. The remaining four genotypes (YM-03-2-2, YM-03-2-5, YM-03-4-11and Yezin-7) scattered away from the origin in the biplot indicating that the genotypes were more sensitive to the environmental effects.

The IPCA scores of a genotype in the AMMI analysis were reported by Guach and Zobel (1966) and Purchase (1997) as indication of the stability of a genotype across environments. The closer the IPCA scores are to zero, the more stable the genotypes are across their testing environments (Yau 1995, Purchase 1997). These results are also similar to those obtained by Tarakanovas and Ruzgus (2006), Misra et al. (2009) and Das et al. (2010).

AMMI II model estimated yield of the genotypes in different environments by the effects of genotype and environment and interaction effects of IPCA 1 and IPCA 2. The AMMI II gave a model fit of $99.98 \%$ for seed yield per plant of tested mungbean genotypes. The genotypes YM-03-2-6 and Yezin-9 were ranked among the top four in all tested environments, and YM-03-2-2 ranked among the top four in two environments, while YM-03-2-5, YM-034-11, Yezin-5 and Yezin-11were ranked the top four in one location. This result indicated that genotypes YM-03-26 and Yezin-9 were high yielding genotypes and possessed broad adaptation to tested environments whereas YM03-2-2 showed wide adaptation to Yezin (DAR) and Sebin Research Farm. Genotypes showing good adaptation to specific environments were YM-03-4-11 for Yezin(DAR), YM-03-2-5 and Yezin-11 for Tatkon Research Farm and Yezin-5 for Sebin Research Farm. 


\section{Conclusion:-}

From the stability analysis of tested mungbean genotypes, it is found that five groups of genotypes across growing environments. YM-03-2-6, Yezin-9 and Yezin-10 produced close to unity $\left(b_{i}=1\right)$ and non significant differences from regression coefficient $\left(b_{i}\right)$ and mean square deviation from regression $\left(S_{d i}^{2}\right)$. Thus, YM-03-2-6 and Yezin-9 were stable varieties with high mean yield whereas Yezin-10 was a stable variety with low mean yield. Genotype Yezin-11, YM-04-M-26, YM-03-4-20, Yezin-5 and Yezin-7 possessed average yield stability with low $S_{d i}^{2}$ value whereas Genotype YM-03-4-11, MAS-1 and YM-03-4-21 produced low, non significant $b_{i}$ and $S_{d i}^{2}$ value. This indicated that the former group was best suited to high yielding environments and the latter group indicated better response to poor environments. Genotype YM-03-2-5 had high $b_{i}$ and $S_{d i}^{2}$ value whereas genotypes YM-03-2-2 produced average mean yield with low $b_{i}$ and high $S_{d i}^{2}$ value. It can be concluded that genotype YM-03-2-5 should be suited to favourable environment and genotype YM-03-2-2 should be adapted to poor environment.

From the results of AMMI analysis, YM-03-2-6 and Yezin -9 possessed higher grand mean yield and stability across environments by being close to the zero of IPCA scores on the basis of AMMI I biplot and minimal interaction with environments on the basis of AMMI II biplot. On the effects of genotype, environment and interaction effects of IPCA 1 and IPCA 2, AMMI II model estimated four top ranking genotypes in each environment such as YM-03-26, Yezin-9, YM-03-2-2 andYM-03-4-11 in Yezin (DAR), YM-03-2-6, YM-03-2-5, Yezin-11and Yezin-9 in Tatkon Research Farm and Yezin-9, YM-03-2-2, YM-03-2-6 and Yezin-5 in Sebin Research Farm. Therefore, YM-03-2-6 and Yezin-9 could be used as broad adaption varieties with high yield in all tested environments whereas YM-03-22 showed wide adaptation to Yezin (DAR) and Sebin Research Farm. Genotypes that could be used as good adaptation to specific environments were YM-03-4-11 for Yezin(DAR), YM-03-2-5 and Yezin-11 for Tatkon Research Farm and Yezin-5 for Sebin Research Farm.

Table 3:- Additive main effect and multiplicative interaction analysis of variance for seed yield per plant of mungbean genotypes across environments

\begin{tabular}{|l|r|r|r|l|r|}
\hline \multicolumn{1}{|c|}{ Source } & df & \multicolumn{1}{c|}{ SS } & \% of SS & MS & $\begin{array}{c}\text { \% of G x E } \\
\text { Interaction SS }\end{array}$ \\
\hline Genotype (G) & 12 & 106.4 & 18.88 & $8.860^{* *}$ & \\
\hline Environment (E) & 2 & 345.9 & 61.40 & $172.950^{* *}$ & \\
\hline G x E Interactions & 24 & 111 & 19.70 & $4.630^{* *}$ & 56.14 \\
\hline IPCA 1 & 13 & 62.3 & 11.06 & $4.800^{* *}$ & 43.85 \\
\hline IPCA 2 & 11 & 48.7 & 8.64 & $4.430^{*}$ & \\
\hline Residuals & 0 & 0 & & & \\
\hline Error & 108 & 206.1 & & 1.91 & \\
\hline
\end{tabular}

Table 4:- Genotype x environment effect (GEE) on seed yield per plant (g) of tested mungbean genotypes in Yezin (DAR), Tatkon and Sebin Research Farm (2011)

\begin{tabular}{|c|c|r|r|r|}
\hline No. & Genotype & Yezin & Tatkon & Sebin \\
\hline 1 & YM 03-2-2 & 0.52 & -1.80 & 1.29 \\
\hline 2 & YM 03-2-5 & 0.31 & 1.23 & -1.54 \\
\hline 3 & YM 03-2-6 & -0.11 & 0.68 & -0.57 \\
\hline 4 & YM 03-4-11 & 1.74 & -0.97 & -0.77 \\
\hline 5 & YM 03-4-20 & -0.25 & 0.67 & -0.42 \\
\hline 6 & YM 03-4-21 & 0.71 & -0.92 & 0.20 \\
\hline 7 & YM 04-M-26 & -0.53 & 1.17 & -0.64 \\
\hline 8 & Yezin - 5 & -0.86 & 0.18 & 0.68 \\
\hline 9 & Yezin - 7 & -1.61 & 0.62 & 0.98 \\
\hline 10 & Yezin - 9 & -0.07 & -0.85 & 0.93 \\
\hline 11 & Yezin - 10 & -0.16 & -0.03 & 0.19 \\
\hline 12 & Yezin - 11 & -0.70 & 0.41 & 0.28 \\
\hline 13 & MAS - 1 & 1.01 & -0.40 & -0.62 \\
\hline
\end{tabular}




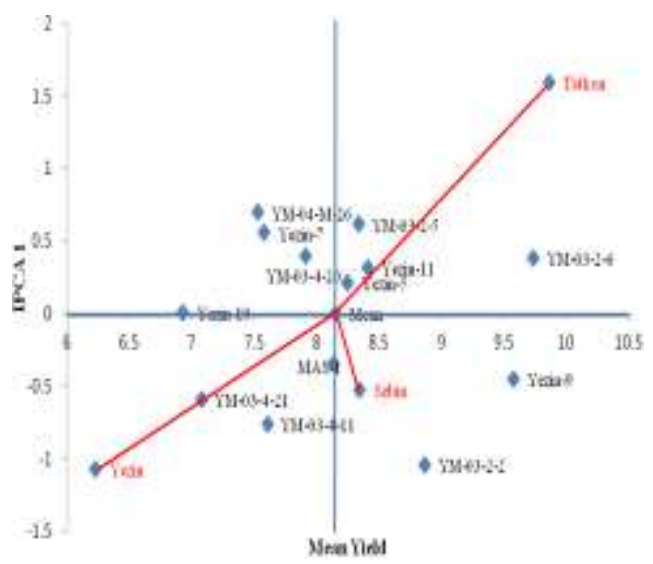

Fig. 2. AMDO I biphat of axain dfects and 60 . interaction of tested mungbtan gevobyes across thret environments

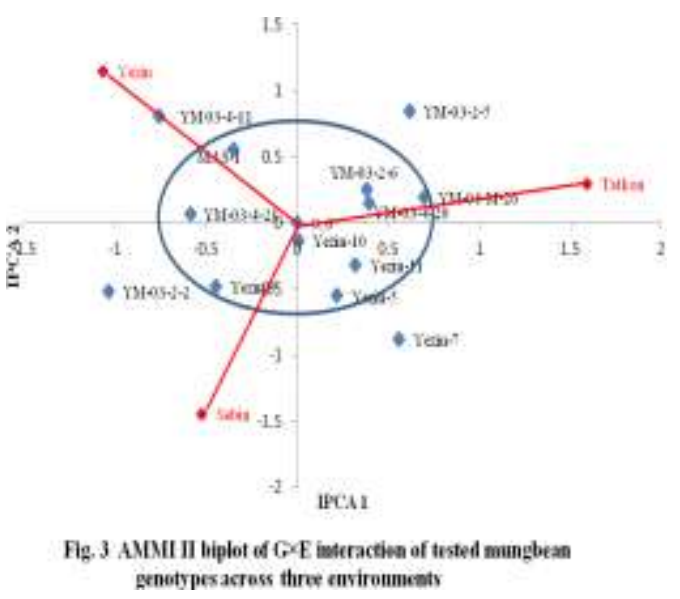

\section{Reference:-}

1. Abo El-Zahab, A.A., M.A. Lakani, D.A. El-Kadi and A.M. Khattab. 1986. Analytical study for the genotypic stability of certain soybean (Glycine Max L.) cultivars. Res. Bull. Fac. of Agric., Cairo Univ. 35: 961987.

2. Agugo, B.A.C and G.O. Chukwu. 2009. Predicting the potential maximum yield of mungbean [Vigna radiata (L.) Wilczek] at different sowing dates in a rain forest location of southeastern Nigeria. EJEAFChe. 8 (9): 730739.

3. Ahmad, J., M.H. Choudhry, S. Salah-ud-Din and M. A. Ali. 1996. Stability for grain yield in wheat. Pak. J. Bot. 28:61-65.

4. Allard , R.W. 1960. Principles of Plant Breeding. John Wiley and Sons, Inc.: New York

5. Berger, J.D., J. Speijers, R.L. Sapra, and U.C. Sood. 2007. Genotype by environment interaction and chickpea improvement. In: Chickpea Breeding and Management. Yadav SS, Redden RJ, Chen W, Sharma B (eds), CAB International. pp. 617-629.

6. Bull, J. K., M. Cooper, I. H. Delacy, K. E. Basford and D. R. Woodruff. 1992. Utility of repeated checks for hierarchial classification of data from plant breeding trials. Field Crop. Res. 30:79-95.

7. Crossa, J. 1990. Statistical analyses of multilocation trials.Adv. Agron. 44: 55-85.

8. Das, S., R.C. Misra, M.C. Patnaik and S.R. Das. 2010. Genotype x environment interaction, adaptability and yield stability of mid - early rice genotypes. Indian J. Agric. Res. 44(2): 104-111.

9. Eberhart, S. A. and W. A. Russell. 1966. Stability parameters for comparing varieties. Crop Science, Madiso., 6(1): 36-40. 
10. Eisemann, R.L, M. Cooper, and D.R. Woodruff. 1990. Beyond the analytical methodology - Better interpretation of genotype-by-environment interaction. In: Kang MS (ed) Genotype-by-environment Interaction and Plant Breeding. Louisiana State University, Baton Rouge, Louisiana. pp. 108-117.

11. Fernandez, G.C.J and S. Shanmugasundaram. 1988. The AVRDC Mungbean Improvement Program: The Past, Present and Future. Proceeding of The Second International Symposium, AVRDC, Shanhua,Tainum.

12. Finlay, K. W. and G. N. Wilkinson. 1963. The analysis of adaptation in a plant breeding program. Australian Journal of Agriculture Research, East Melbourne. 14(6): 742- 754.

13. Gauch, H.G. and Zobel, R.W. 1996. AMMI analysis of yield trials: In: karg, M.S. and Gauch, H.G (eds). Genotype by environment interaction. CRC Press, Bocarator, Florida, USA. pp. 85-

14. Gauch, H.G., 1992. Statistial analysis of regional yield dat: AMMI analysis of factorial designs. Amsterdam, Elsevier.

15. Lai, M.S., S.K. Mehta and S.C. Pandya. 1974. Stability of performance of soybean varieties in Madhya Pradesh. Indian J. Agric. Sci. 44: 217-220.

16. Misra, R.C., S. Das and M.C. Patnaik. 2009. AMMI model analysis of stability and adaptability of late duration finger millet (Eleusine coracana) genotypes. World Appl. Sci. J. 6(12): 1650 - 1654.

17. MOAI (Ministry of Agricultural and Irrigation). 2011. Myanmar Agriculture in Brief. Ministry of Agricultural and Irrigation, Nay Pyi Taw, Myanmar.

18. Nassib, A.M., S.A. Khalil and A.M. Khattab. 1986. Genotypic stability for advanced series of field bean Vicia faba L. genotypes. Proc. Conf. Agron., Alex., Egypt. 2: 401-416.

19. Omar, M.A., A.M. Abdel-Hakim and M.M. El-Hady. 1999. Stability parameters for faba bean genotypes as criteria for response to environmental conditions. Annals, Agric. Sci., Ain-Shams Univ., Cairo. 44 (1):173-188.

20. Piepho, H.P. 1998. Methods for comparing the yield stability of cropping systems- a review. Journal of Agronomy Crop Sci. 180: 193-213.

21. Poehlman, J.M. 1991. The Mungbean. Oxford and IBH Publishing Co. NewDelhi.

22. Purchase J.L. 1997. Parametric analysis to describe genotype $x$ environment interaction and yield stability in winter wheat. Ph.D. Thesis, Department of Agronomy, Faculty of Agriculture of the University of the Free State, Bloemfontein, South Africa.

23. Raffi, S. A., M. A. Newaz and N. Khan. 2004. Stability analysis for pod and seed production in dry beans (Phaseolus vulgaris L.). Asian J. Plant Sci. 3(2):239-242.

24. Redden, R.J.; I.H. DeLacy; D.G. Butler and T. Usher. 2000. Analysis of line x environment interactions for yield in navy beans. 2. Pattern analysis of lines and environment within years. Australian Journal of Agric. Re., 51:607-617.

25. Sabah, M.A, M.M. El-hady, A.M.S.A. El-Taweel and E.H. El-Harty. 2007. Stability statistics of some faba bean genotypes. Annals of Agric. Sc., Monshtohor. 45(2): 525-544.

26. Singh, R. J. and T. Hymowitz. 2001. Exploitation of wild potential Glycine species for improving the soybean. In: Bhatnagar P. S. (ed.), Proceedings of India Soy Forum. pp 58-61.

27. Tarakanovas, P. and V. Ruzgus. 2006. Additive main effect and multiplicative interaction analysis of grain yield of wheat varieties in Lithuania. Agro. Res. 4(1): 91 - 98.

28. Tarakanovas, P. and V. Ruzgus. 2006. Additive main effect and multiplicative interaction analysis of grain yield of wheat varieties in Lithuania. Agro. Res. 4(1): 91 - 98.

29. Truberg, B., and M. Huehn. 2000. Contribution to the analysis of genotype by environment interactions: Comparison of different parametric and non-parametric tests for interactions with emphasis on crossover interactions. Agron. Crop Sci. 185:267-274.

30. Vargas, M., J. Crossa, K. Sayre, M. Reynolds, M. Ramirez and M. Talbot. 1998. Interpreting genotype $\mathrm{x}$ interaction in wheat by partial least squares regression. Crop Sci. 38: 679-689.

31. Yau, S.K. 1995. Regression and AMMI analyses of genotype-environment interactions: an empirical comparison. Agron. J. 87:121-126.

32. Zobel, R.W., M.J. Wright and H.G. Gauch. 1988. Statistical analysis of a yield trial. Agro. J. 80: 388-393. 